\title{
Application of Weighted Additive Fuzzy Goal Programming Approach to Quality Control System Design
}

\author{
Mohammed. Mekidiche. \\ Faculty of Economics and Commerce, University of Tlemcen, -Maghnia Annex-Algeria \\ E-mail: mkidiche@yahoo.fr \\ Mostefa Belmokaddem \\ Faculty of Economics and Commerce,University of Tlemcen, Algeria \\ E-mail: belmo_mus@yahoo.fr
}

\begin{abstract}
The problem of decision-making in designing a quality control system (QCS), is one of the most difficult problems decisions facing the manager in the industrial firms, this problem of decision requires of fixing the levels of inputs and variables that meet the required output specifications. in the context of the problem a QCS, the parameters can be imprecise and expressed through intervals or fuzzy. The aim of this study is to presents the formulation for designing a QCS based on Weighted fuzzy goal programming (WAFGP) developed by Yaghoobi and Tamiz [12] and Yaghoobi et al [13], the advantage of the proposed formulation as a linear, use all types of membership functions and integrate explicitly the decision-maker's preference. Finally, we compare the results of our model with the major important mathematical models used in the QCS It has been shown that the best model.
\end{abstract}

Index Terms - Fuzzy Goal Programming, Additive Approach, Quality Control System

\section{Introduction}

Even though some real-world problems can be reduced to a matter of a single objective very often it is hard to define all the aspects in terms of a single objective. Defining multiple objectives often gives a better idea of the task. Multi objective optimization has been available for about two decades, and its application in real-world problems is continuously increasing. In contrast to the plethora of techniques available for single-objective optimization, relatively few techniques have been developed for multi objective optimization, Goal programming(GP) is one of the most important methods of Multi objective optimization, it is an extension to linear programming . the basic idea is to establish a specific numeric goal for each of the objectives, formulate an objective function for each objective, then seek a solution that minimizes the significance of GP lies in its perspective of sharing goals with their priorities and providing an optimal solution, keeping in line the goals and their priorities. Where linear programming usually deals with a onedimensional objective such as profit maximization, goal programming solves multiple and frequently conflicting objectives, such as profitability, liquidity, and solvency. Some of the many recent applications of GP in management have been considered. In this paper we introduce this approach, describe its underlying philosophy for QCS in the presence of certain features which is a complex decision making process.

Sengupta [11] proposed a lexicographic GP model for QCS design in paper industry, he determined the levels of inputs and process variables in order to meet a required specification of output which is common for QCS design. Schniederjans and Karuppan [10] developed a new formulation based on GP for QCS design in service organizations by using a zero-one GP model to help in select the "best" set of quality control instruments for customer data collection purposes. Badri [1] proposed an extension of Schniederjans and Karuppan's model by combining the Analytic Hierarchy Process method and GP model for designing QCS in service organizations. Lee and Wen [7] proposed an application of fuzzy goal programming (FGP) which has been developed by Hannan [4] for Water Quality Management in a River Basin. Sadok et al [3] proposed two formulations for designing QCS based on the imprecise GP model, first based on Hannan[4] approach (Minmax approach) and second based on GP with satisfaction functions which was later developed by Martel and Aouni [8], they applied his formulations of paper industry.

This study presents two formu lations of QCS design based on additive FGP, the first was developed by Hannan(1981) it minimized an additive summation of deviations, and the second was developed by Yaghoobi and Tamiz [12] and Yaghoobi et al [13] and its 
application of paper industry is the same example that had been developed by Sengupta [11].

\section{GP Approach for Designing to QCS in the Paper Factory}

\subsection{Sengupta's Approach}

Sengupta(1981) described a process control problem in the paper industry in which levels of inputs variables $\left(X_{1} ; \ldots ; X_{l}\right)$ and process variables $\left(R_{1} ; \ldots ; R_{k}\right)$ were to be fixed in order to meet required specifications of several output characteristics $\left(Y_{1} ; \ldots ; Y_{r}\right)$. The permissible range of values for inputs and process variables were predetermined. The output characteristics to be achieved are either specified as a permissible range of values or are of the 'close to' type. The problem, as stated, is to find a solution in which the input levels and process variables meet all the specifications on output characteristics subject to their constraints and if no such solution exists, then to find the best compromise solution.

The relationship between the output quality characteristics with the inputs and the process variables established through multiple linear regression analysis. These relationships are then used in a GP formulation with a pre-emptive priority structure to solve the problem.

The details of the input, process variables and output variables in the paper industry are illustrated in Table 1.

Table 1: Target specification for input characteristic, process variables, and output characteristics

\begin{tabular}{|l|l|l|}
\hline \multicolumn{2}{|c|}{ Specification/permissible limit } & {$[20,40]$} \\
\hline Input characteristic & $\left(X_{1}\right)$ Hardwood $(\%)$ & {$[140,175]$} \\
\hline \multirow{5}{*}{ Process variables } & $\left(R_{1}\right)$ Upper cooking zone temperature $\left({ }^{\circ} \mathrm{C}\right)$ & {$[140,173]$} \\
& $\left(R_{2}\right)$ Lower cooking zonetemperature $\left({ }^{\circ} \mathrm{C}\right)$ & {$[2,0,4,4]$} \\
& $\left(R_{3}\right)$ LP steam pressure $\left(\mathrm{kg} / \mathrm{cm}^{2}\right)$ & {$[8,0,20,5]$} \\
& $\left(R_{4}\right)$ HP steam pressure $\left(\mathrm{kg} / \mathrm{cm}^{2}\right)$ & {$[20,35]$} \\
& $\left(R_{5}\right)$ Active alkali as $\mathrm{NaOH}(\%)$ & {$[13,25]$} \\
& $\left(R_{6}\right)$ Sulphidity of white liquor $(\%)$ & {$[12,5,18,7]$} \\
\hline \multirow{5}{*}{ Output characteristics } & $\left(R_{7}\right)$ Alkali index $($ no $)$ & {$[16,18]$} \\
& $\left(Y_{1}\right)$ K-number & Close to 35 \\
& $\left(Y_{2}\right)$ Burst factor & Close to 5000 \\
\hline
\end{tabular}

The problem was to fix the levels of the input and the process variables so that specification is met. A followup study was undertaken linking the input with the output through the process variables. 46 sets of such data were collected over a period of 13 days. Multiple linear regression analysis was undertaken and the following relationships were obtained.

$$
\begin{aligned}
& Y_{1}=22.84+0.06 X_{1}-0.05 R_{1}+0.004 R_{2}- \\
& 0.67 R_{3}+0.24 R_{4}-0.13 R_{5}+0.19 R_{6}-0.18 R_{7}
\end{aligned}
$$

(Multiple correlation coefficien $t=0.74$ )

$Y_{2}=38.94+0.05 X_{1}-0.02 R_{1}+0.002 R_{2}+$ $1.67 R_{3}+0.21 R_{4}+0.06 R_{5}+0.02 R_{6}-0.69 R_{7}$

(Multiple correlation coefficien $t=0.72$ )

$Y_{3}=3273.4-24.37 X_{1}+9.997 R_{1}+$

$8.48 R_{2}-268.68 R_{3}+120.92 R_{4}+$

$67.27 R_{5}+27.89 R_{6}-138.46 R_{7}$

(Multiple correlation coefficien $t=0.66$ )
To formulate this problem as a GP problem, the first setup required to be transformed to obtain one sided specification only, and these transformed variables are used in the GP formulation described. For example, the input-hardwood percentage $\left(X_{1}\right)$ should be between 20 and 40 . This is transformed as

$$
X_{1}^{\prime}=X_{1}-20 \leq 20,
$$

and in other variables as

$$
R_{3}^{\prime}=R_{3}-2 \leq 2.4, Y_{3}^{\prime}=Y_{3} \approx 5000,
$$

and next setup modified regression equation for example:

$$
\begin{aligned}
& Y_{1}^{\prime}=-0.334+0.06 X_{1}^{\prime}-0.05 R_{1}^{\prime}+0.004 R_{2}^{\prime}-0.67 R_{3}^{\prime} \\
& +0.24 R_{4}^{\prime}-0.13 R_{5}^{\prime}+0.19 R_{6}^{\prime}-0.18 R_{7}^{\prime}
\end{aligned}
$$

The Pre-emptive Priority factor is the K-number most important characteristic to be fulfilled gets the top priority. Priorities for others which in the fixed by the management after giving due consideration to the quality aspect as well as the ease of adjusting and 
modifying the levels of those variables. Sengupta [11] has formulated the GP problem as follows:

$\operatorname{Min} Z=P_{1} \delta_{Y_{1}^{\prime}}^{-}+P_{2}\left(\delta_{Y_{2}^{\prime}}^{-}+\delta_{Y_{2}^{\prime}}^{+}\right)+P_{3}\left(\delta_{Y_{3}^{\prime}}^{-}+\delta_{Y_{3}^{\prime}}^{+}\right)$

$+P_{4}\left(\delta_{R_{4}^{\prime}}^{-}+\delta_{R_{7}^{\prime}}^{-}\right)+P_{5}\left(\delta_{X_{1}^{\prime}}^{-}+\delta_{R_{1}^{\prime}}^{-}+\delta_{R_{2}^{\prime}}^{-}+\delta_{R_{3}^{\prime}}^{-}+\delta_{R_{5}^{\prime}}^{-}+\delta_{R_{6}^{\prime}}^{-}\right)$

Subject to:

Output constraints:

$$
\begin{aligned}
& Y_{1}^{\prime}+\delta_{Y_{1}^{\prime}}^{-}=2 \text { i.e } \\
& 0.06 X_{1}^{\prime}-0.05 R_{1}^{\prime}+0.004 R_{2}^{\prime}-0.67 R_{3}^{\prime}+ \\
& 0.24 R_{4}^{\prime}-0.13 R_{5}^{\prime}+0.19 R_{6}^{\prime}-0.18 R_{7}^{\prime}+\delta_{Y_{1}^{\prime}}^{-}=2.334 \\
& Y_{2}^{\prime}+\delta_{Y_{2}^{\prime}}^{-}-\delta_{Y_{2}^{\prime}}^{+}=35 \text { i.e } \\
& 0.05 X_{1}^{\prime}-0.02 R_{1}^{\prime}+0.002 R_{2}^{\prime}+1.67 R_{3}^{\prime}+0.21 R_{4}^{\prime} \\
& +0.06 R_{5}^{\prime}+0.02 R_{6}^{\prime}-0.69 R_{7}^{\prime}+\delta_{Y_{2}^{\prime}}^{-}-\delta_{Y_{2}^{\prime}}^{+}=0.6085 \\
& Y_{3}^{\prime}+\delta_{Y_{3}^{\prime}}^{-}-\delta_{Y_{3}^{\prime}}^{+}=5000 \text { i.e } \\
& 24.37 X_{1}^{\prime}+9.997 R_{1}^{\prime}+8.48 R_{2}^{\prime}-268.68 R_{3}^{\prime}+120.92 R^{\prime} \\
& { }_{4}+67.89 R_{6}^{\prime}-27.89 R_{6}^{\prime}-138.46 R_{7}^{\prime}+\delta_{Y_{3}^{\prime}}^{-}-\delta_{Y_{3}^{\prime}}^{+}=726.139
\end{aligned}
$$

Input cons traint

$$
X_{1}^{\prime}+\delta_{X_{1}^{\prime}}^{-}=20
$$

Process constraints

$R_{1}^{\prime}+\delta_{R_{1}^{\prime}}^{-}=35 ; \quad R_{2}^{\prime}+\delta_{R_{2}^{\prime}}^{-}=33 ;$

$R_{3}^{\prime}+\delta_{R_{3}^{\prime}}^{-}=2.4 ; \quad R_{4}^{\prime}+\delta_{R_{4}^{\prime}}^{-}=12.5 ; \quad R_{5}^{\prime}+\delta_{R_{5}^{\prime}}^{-}=15 ;$

$R_{6}^{\prime}+\delta_{R_{6}^{\prime}}^{-}=12 ; \quad R_{7}^{\prime}+\delta_{R_{7}^{\prime}}^{-}=6.2 ;$

With: $X_{1}^{\prime} \geq 0 ; \quad R_{t}^{\prime} \geq 0, \quad t=1,2, . ., 7$

The optimal solution is:

$X_{1}=44 ; R_{1}=160 ; R_{2}=176 ; R_{3}=3 ;$

$R_{4}=11.5 ; R_{5}=28 ; R_{6}=23$ and $R_{7}=18$.

This solution result in

$Y_{1}=16.42 ; Y_{2}=35.43$ and $Y_{3}=5910$.

\subsection{GP with Satisfaction Functions Approach for Designing a QCS}

Sadok et al [3] used a GP model with satisfaction function proposed by Martel and Aouni [8] for designing QCS in the paper industry. The general shape of the satisfaction function is shown in (fig 1).

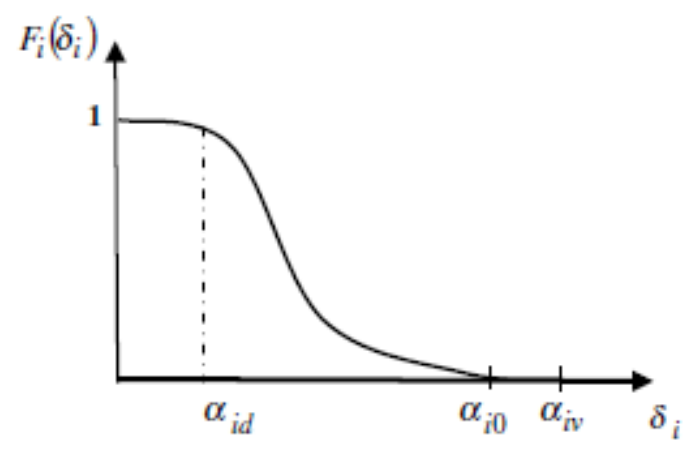

Fig. 1: General shape of the satisfaction function

Were $F_{i}\left(\delta_{i}\right)$ : satisfaction function associated with deviations $\delta_{i}, \alpha_{i d}$ : indifference threshold; $\alpha_{i 0}$ : dissatisfaction threshold; $\alpha_{i v}$ :veto threshold.

The GP model with satisfaction function proposed by sadoket al [2] can be formulated as follows :

Maximize $Z=\sum_{i=1}^{r}\left(w_{Y_{i}}^{+} F_{Y_{i}}^{+}\left(\delta_{Y_{i}}^{+}\right)+w_{Y_{i}}^{-} F_{Y_{i}}^{-}\left(\delta_{Y_{i}}^{-}\right)\right)+$

$\sum_{j=1}^{l}\left(w_{X_{j}}^{+} F_{X_{j}}^{+}\left(\delta_{X_{j}}^{+}\right)+w_{X_{j}}^{-} F_{X_{j}}^{-}\left(\delta_{X_{j}}^{-}\right)\right)$

$+\sum_{t=1}^{k}\left(w_{R_{t}}^{+} F_{R_{t}}^{+}\left(\delta_{R_{i}}^{+}\right)+w_{R_{t}}^{-} F_{R_{t}}^{-}\left(\delta_{R_{t}}^{-}\right)\right)$

subject to :

$Y_{i}+\delta_{Y_{i}}^{-}-\delta_{Y_{i}}^{+}=g_{Y_{i}} \quad($ for $i=1,2, \ldots, r)$

$X_{j}+\delta_{X_{j}}^{-}-\delta_{X_{j}}^{+}=g_{X_{j}}($ for $j=1,2, \ldots, l)$

$R_{t}+\delta_{R_{t}}^{-}-\delta_{R_{t}}^{+}=g_{R_{t}} \quad($ for $t=1,2, \ldots, k)$

with $\delta_{Y_{i}}^{-}$and $\delta_{Y_{i}}^{+} \leq \alpha_{i v}$

$\delta_{X_{j}}^{-}$and $\delta_{R_{t}}^{+} \leq \alpha_{i v}$

$\delta_{R_{t}}^{-}$and $\delta_{R_{t}}^{+} \leq \alpha_{i v}$

$\delta_{Y_{i}}^{-}, \delta_{Y_{i}}^{+}, \delta_{X_{j}}^{-}, \delta_{X_{j}}^{+}, \delta_{R_{i}}^{-}, \delta_{R_{t}}^{+}, Y_{i}, X_{j}$ and $R_{t} \geq 0$

Where $w_{i}$ express the relative importance of the objectives.

Sadok et al [3] have used this model in the papers industry, the optimal solution is:

$X_{1}=40 ; R_{1}=158 ; R_{2}=145 ; R_{3}=3.387$;

$R_{4}=9.321 ; R_{5}=23 ; R_{6}=23$ and $R_{7}=18.152$

This solution results in

$Y_{1}=16 ; Y_{2}=35$ and $Y_{3}=5052,356$ 
Despite the good results obtained by Sadok et al but that the formulation in problem of a QCS designing the use of GP with satisfaction function proposed by Martel and Aouni [8] we will get to the formulation of nonlinear programming (LP), to be converted to the LP this is what makes the model's contains a many constraints, as it would be very difficult to be applied in the firms that produce some products which contain many inputs and process variables.

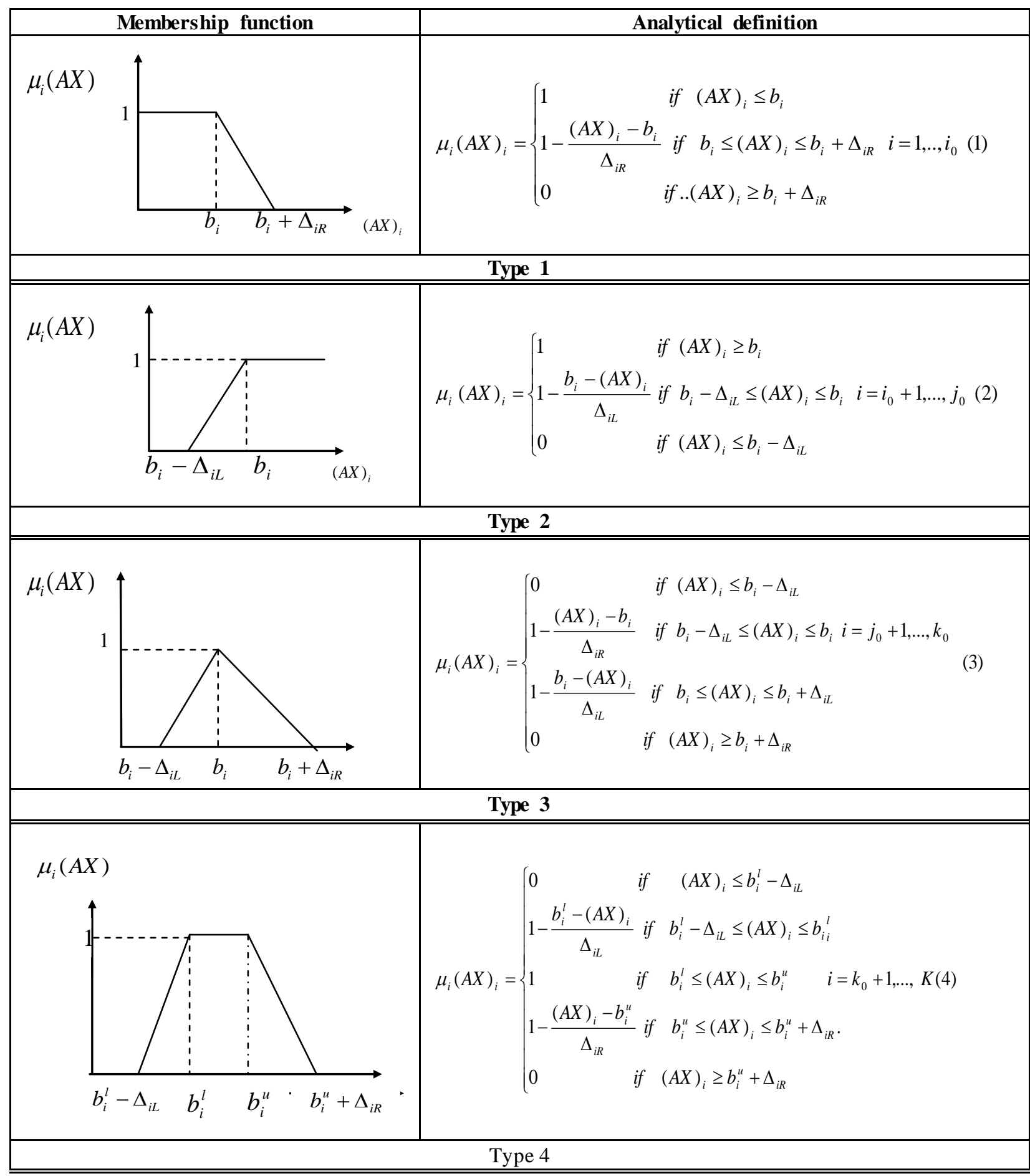

Fig 2 : A type of linear membership functions

\section{Fuzzy Goal Programming}

A useful tool for dealing with imprecision is fuzzy set theory [14] .An objective with an imprecise aspiration level can be treated as a fuzzy goal. Initially,
Narasimhan [9] incorporated fuzzy set theory in GP and presented an FGP model. Hannan [4] simplified the Narasimhan method to an equivalent simple LP. These pioneering works led to extensive research in the use and application of FGP to real life problems. 
To solve FGP problems various models based on different approaches have been proposed. A survey and classification of FGP models had been presented by Chanas and Kuchta [2].There are three types of fuzzy goals which are the most common. The following FGP model contains these fuzzy goals.

$$
\begin{aligned}
& \operatorname{OPT}(A X)_{i} \underset{\approx}{\leq} b_{i} \quad i=1, . ., i_{O} \\
& (A X)_{i} \underset{\approx}{\geq b_{i}} i=i_{O}+1, \ldots, j_{0} \\
& (A X)_{i} \cong i=j_{O}+1, \ldots, K \\
& X \in C_{S} \text {, }
\end{aligned}
$$

Where OPT means finding an optimal decision $X$ such that all fuzzy goals are satisfied, $(A X)_{i}=$ $\sum_{j=1}^{n} a_{i j} x_{j} \quad i=1, \ldots, k, b_{i}$ is the aspiration level for i.th goal.

\subsection{Membership Functions}

Narasimhan [9] and Hannan [4], were the first to give a FGP formulation by using the concept of the membership function. These functions are defined on the interval $[0,1]$. So, the membership function for the $i$-th goal have a value of 1 when this goal is attained and the decision maker's is totally satisfied; otherwise the membership functions assume a value between 0 and 1 .

Linear membership functions are used in theory and practice more than other types of membership functions. For the above four types of fuzzy goals linear membership functions are defined and depicted as follows ( Fig. 2).

\section{FGP for Designing a QCS}

\subsection{FGP for Designing a QCS Using Hannan Approach}

To deal with FGP problems some models use the concept of deviational variables in GP. These models try to minimize an additive summation of deviations from imprecise aspiration levels of fuzzy goals.

Hannan [4] introduced the first formulation in the FGP his model is only isosceles triangular linear membership function (Fig1-type3) which considered, $\left(\Delta_{i L}=\Delta_{i R}\right)$ indicates both left and right admissible violations for the $i$ th fuzzy goal. $\delta_{i}^{-}$and $\delta_{i}^{+}$, Hannan [4] proposed two approaches in the FGP (Minmax approach and Additive approach), the first approach Maximizes the degree of membership functions and the seconds Minimizes an additive summation of deviations. The application of two objective functions to Hannan [4] for designing the QCS in the paper factory is as follows:
- Minmax approach: maximize degree of memberships functions $\mu_{i}$ its model is as follows:

$\operatorname{Max} z=\mu$

subject to

$-0,06 X_{1}+0,05 R_{1}-0,004 R_{2}+0,67 R_{3}-0,24 R_{4}$
$+0,13 R_{5}-0,19 R_{6}+0,18 R_{7}-\delta_{y_{1}}^{-}+\delta_{y_{1}}^{+}=5,84$
$-0,025 X_{1}+0,01 R_{1}-0,001 R_{2}-0,835 R_{3}-0,105 R_{4}$
$-0,03 R_{5}-0,01 R_{6}+0,345 R_{7}-\delta_{y_{2}}^{-}+\delta_{y_{2}}^{+}=1,97$

$-0,0812 X_{1}+0,033 R_{1}+0,028 R_{2}-0,895 R_{3}+0,403 R_{4}$

$+0,224 R_{5}+0,092 R_{6}-0,461 R_{7}-\delta_{y_{3}}^{-}+\delta_{y_{3}}^{+}=5,753$

$0,1 X_{1}+\delta_{X_{1}}^{-}-\delta_{X_{1}}^{+}=3$

$0,0571+\delta_{R_{1}}^{-}-\delta_{R_{1}}^{+}=9$

$0,0606 R_{2}+\delta_{R_{2}}^{-}-\delta_{R_{2}}^{+}=9,485$

$0,833 R_{3}+\delta_{R_{3}}^{-}-\delta_{R_{3}}^{+}=2,666$

$0,16 R_{4}+\delta_{R_{4}}^{-}-\delta_{R_{4}}^{+}=2,28$

$0,133 R_{5}+\delta_{R_{5}}^{-}-\delta_{R_{5}}^{+}=3,666$

$0,166 R_{6}+\delta_{R_{6}}^{-}-\delta_{R_{6}}^{+}=3,166$

$0,322 R_{7}+\delta_{R_{7}}^{-}-\delta_{R_{7}}^{+}=5,032$

$\mu+\delta_{y_{i}}^{-}+\delta_{y_{i}}^{+} \leq 1$

$\mu+\delta_{X_{1}}^{-}+\delta_{X_{1}}^{+} \leq 1$

$\mu+\delta_{R_{t}}^{-}+\delta_{R_{t}}^{+} \leq 1$

$\mu, \delta_{y_{i}}^{-}, \delta_{y_{i}}^{+}, \delta_{X_{1}}^{-}, \delta_{X_{1}}^{+}, \delta_{R_{t}}^{-}, \delta_{R_{t}}^{+}, Y_{i}, X_{1}$ and $R_{t} \geq 0$

(For $i=1,2,3$ and $t=1,2, . ., 7)$.

Using the LINGO package, the obtained optimal solution is as follows:

$X_{1}=35,886$,

$R_{1}=147,197, R_{2}=145, R_{3}=3,04, R_{4}=10,57$,

$R_{5}=22,249, R_{6}=22,249, R_{7}=18,152$

This solution results in to

$Y_{1}=16,455, Y_{2}=36,177, Y_{3}=5229,926$.

- Additive approach: minimize a additive summation of deviations: the objective function and constraints in their model is as follows:

$\operatorname{Min} Z=\sum_{i=1}^{3}\left(\delta_{Y_{i}}^{-}+\delta_{Y_{i}}^{+}\right)+\sum_{j=1}^{1}\left(\delta_{X_{i}}^{-}+\delta_{X_{i}}^{+}\right)+\sum_{t=1}^{7}\left(\delta_{R_{i}}^{-}+\delta_{R_{i}}^{+}\right)$

Subject to: Constraints (1)-(15).

The optimal solution is as follows: $X_{1}=36,288$, $R_{1}=139,99, R_{2}=156,502, R_{3}=3,2, R_{4}=11,605$ 
$R_{5}=20, R_{6}=18,99, R_{7}=18,302$ This solutions is yielding to $Y_{1}=17,04, Y_{2}=35, Y_{3}=5056,82$.

\subsection{Weighted Additive Fuzzy Goal Programming (WAFGP) for Designing a QCS}

\subsubsection{WAFGP models}

Yaghoobi and Tamiz [12] and Yaghoobi et al [13] who proposed other approaches for solving FGP problems with unequal weights can be formulated as a single LP problem with the concept of tolerance, The attempt to extend Kim and Whang [6] model by introducing an LP model that is able to use all types of memberships functions (type1-type4) their model can be formulated as follow:

$\operatorname{Min} z=\sum_{i=1}^{i_{0}} w_{i} \frac{\delta_{i}^{+}}{\Delta_{i R}}+\sum_{i=i_{0}+1}^{j_{O}} w_{i} \frac{\delta_{i}^{-}}{\Delta_{i L}}+\sum_{i=j_{o}+1}^{K} w_{i}\left(\frac{\delta_{i}^{-}}{\Delta_{i L}}+\frac{\delta_{i}^{+}}{\Delta_{i R}}\right)$

subject to:

$\begin{array}{ll}(A X)_{i}-\delta_{i}^{+} \leq b_{i} & i=1, . ., i_{o} \\ \mu_{i}+\frac{\delta_{i}^{+}}{\Delta_{i R}}=1 & i=1, . ., i_{o}\end{array}$

$$
\begin{array}{ll}
(A X)_{i}+\delta_{i}^{-} \geq b_{i} & i=i_{0}+1, . ., j_{0} \\
\mu_{i}+\frac{\delta_{i}^{-}}{\Delta_{i L}}=1 & i=i_{0}+1, . ., j_{0} \\
(A X)_{i}+\delta_{i}^{-}-\delta_{i}^{+}=b_{i} & i=j_{o}+1, . ., k_{0} \\
\mu_{i}+\frac{\delta_{i}^{-}}{\Delta_{i L}}+\frac{\delta_{i}^{+}}{\Delta_{i R}}=1 & i=j_{o}+1, . ., K \\
(A X)_{i}+\delta_{i}^{-}-\delta_{i}^{+}=b_{i} & i=j_{o}+1, . ., K \\
(A X)_{i}-\delta_{i}^{+} \leq b_{i}^{u} & i=k_{0}+1, . ., K \\
(A X)_{i}+\delta_{i}^{-} \geq b_{i}^{l} & i=k_{0}+1, . ., K \\
\mu_{i}, \delta_{i}^{-}, \delta_{i}^{+} \geq 0 & i=1, . ., K \\
X \in C_{s} &
\end{array}
$$

Where $C_{s}$ is an optional set of hard constraints as found in LP.

The advantages of the new model are :

- the WAFGP developed by Yaghoobi et al (2008) wich can be used for these types of membership functions .

- the new formulation determines the degree of membership function for every variable.

- the optimal solution of new model is equal to the degree of membership function for ith fuzzy goal.

Table 2: type and data of memberships function for every variables

\begin{tabular}{|l|l|l|l|l|}
\hline \multicolumn{1}{|c|}{ Type of variables } & \multicolumn{1}{|c|}{ Variables } & $\begin{array}{c}\text { Type of memberships } \\
\text { functions }\end{array}$ & \multicolumn{2}{c|}{ Data of membership functions } \\
\hline Input characteristic & $\left(X_{1}\right)$ & Type 3 & $\left(\Delta_{i L}, b_{i}, \Delta_{i R}\right)$ & $(15,15,5)$ \\
\hline \multirow{5}{*}{ Process variables } & $\left(R_{1}\right)$ & Type 4 & $\left(b_{i}^{l}, \Delta_{i L}, b_{i}^{u}, \Delta_{i R}\right)$ & $(158,18,170,5)$ \\
& $\left(R_{2}\right)$ & Type 3 & $\left(\Delta_{i L}, b_{i}, \Delta_{i R}\right)$ & $(4,144,29)$ \\
& $\left(R_{3}\right)$ & Type 3 & $\left(\Delta_{i L}, b_{i}, \Delta_{i R}\right)$ & $(1,3,1.4)$ \\
& $\left(R_{4}\right)$ & Type 4 & $\left(b_{i}^{l}, \Delta_{i L}, b_{i}^{u}, \Delta_{i R}\right)$ & $(2,10.5,10)$ \\
& $\left(R_{5}\right)$ & Type 3 & $\left(\Delta_{i L}, b_{i}, \Delta_{i R}\right)$ & $(7.5,27.5,7.5)$ \\
& $\left(R_{6}\right)$ & Type 3 & $\left(\Delta_{i L}, b_{i}, \Delta_{i R}\right)$ & $(6,19,6)$ \\
& $\left(R_{7}\right)$ & Type 4 & $\left(b_{i}^{l}, \Delta_{i L}, b_{i}^{u}, \Delta_{i R}\right)$ & $(3.1,15.6,3.1)$ \\
\hline \multirow{5}{*}{ Output characteristics } & $\left(Y_{1}\right)$ & Type 4 & $\left(b_{i}^{l}, \Delta_{i L}, b_{i}^{u}, \Delta_{i R}\right)$ & $(16,0,5,18,0,5)$ \\
& $\left(Y_{2}\right)$ & Type 3 & $\left(\Delta_{i L}, b_{i}, \Delta_{i R}\right)$ & $(2,35,2)$ \\
& $\left(Y_{3}\right)$ & Type 3 & $\left(\Delta_{i L}, b_{i}, \Delta_{i R}\right)$ & $(100,5000,100)$ \\
\hline
\end{tabular}

\subsubsection{Application of WAFGP for designing a QCS in the papers industry}

The application of the previous model will be illustrated through the same example of the paper industry. First we will present the membership functions related to each specification (objective), and then we will define the type of membership functions. The details of the type of membership functions of input, process variables and output are shown in Table 2.

Based on the above information (Table 2) and using a methods developed by Yaghoobi and Tamiz [12], and 
Yaghoobi et al [13] the by WAFGP formulation for QCS in the paper factory is as follows:

$$
\begin{aligned}
& \text { Min } z=\left(\frac{\delta_{Y_{1}}^{-}+\delta_{Y_{1}}^{+}}{0,5}\right)+\left(\frac{\delta_{Y_{2}}^{-}+\delta_{Y_{2}}^{+}}{2}\right)+\left(\frac{\delta_{Y_{3}}^{-}+\delta_{Y_{3}}^{+}}{100}\right) \\
& +\left(\frac{\delta_{X_{1}}^{-}}{15}+\frac{\delta_{X_{1}}^{+}}{5}\right)+\left(\frac{\delta_{R_{1}}^{-}}{18}+\frac{\delta_{R_{1}}^{+}}{5}\right)+\left(\frac{\delta_{R_{2}}^{-}}{4}+\frac{\delta_{R_{2}}^{+}}{29}\right) \\
& +\left(\frac{\delta_{R_{3}}^{-}}{1}+\frac{\delta_{R_{3}}^{+}}{1,4}\right)+\left(\frac{\delta_{R_{4}}^{-}}{2}+\frac{\delta_{R_{4}}^{+}}{10,5}\right)+\left(\frac{\delta_{R_{5}}^{-}+\delta_{R_{5}}^{+}}{7,5}\right) \\
& +\left(\frac{\delta_{R_{6}}^{-}+\delta_{R_{6}}^{+}}{6}\right)+\left(\frac{\delta_{R_{7}}^{-}+\delta_{R_{7}}^{+}}{3,1}\right)
\end{aligned}
$$

subject to:

$$
\begin{aligned}
& -0,06 X_{1}+0,05 R_{1}-0,004 R_{2}+0,67 R_{3}-0,24 R_{4} \\
& +0,13 R_{5}-0,19 R_{6}+0,18 R_{7}-\delta_{y_{1}}^{-} \geq 5,84 \\
& -0,06 X_{1}+0,05 R_{1}-0,004 R_{2}+0,67 R_{3}-0,24 R_{4} \\
& +0,13 R_{5}-0,19 R_{6}+0,18 R_{7}+\delta_{y_{1}}^{+} \leq 6,34 \\
& -0,05 X_{1}+0,02 R_{1}-0,002 R_{2}-1,67 R_{3}-0,21 R_{4} \\
& -0,06 R_{5}-0,02 R_{6}+0,69 R_{7}-\delta_{y_{2}}^{-}+\delta_{y_{2}}^{+}=3,94 \\
& -24,37 X_{1}+9,997 R_{1}+8,48 R_{2}-268,68 R_{3}+120,92 R_{4} \\
& +67,27 R_{5}+27,89 R_{6}-138,46 R_{7}-\delta_{y_{3}}^{-}+\delta_{y_{3}}^{+}=1726,6 \\
& X_{1}+\delta_{X_{1}}^{-}-\delta_{X_{1}}^{+}=35 \\
& R_{1}-\delta_{R_{1}}^{+} \leq 170 \\
& \mu_{4}+\left(\frac{\delta_{X_{1}}^{-}}{15}+\frac{\delta_{X_{1}}^{+}}{5}\right)=1 \\
& R_{1}+\delta_{R_{1}}^{-} \geq 158 \\
& R_{2}+\delta_{R_{2}}^{-}-\delta_{R_{2}}^{+}=144 \\
& R_{3}+\delta_{R_{3}}^{-}-\delta_{R_{3}}^{+}=3 \\
& R_{4}+\delta_{R_{4}}^{-}-\delta_{R_{4}}^{+}=10 \\
& R_{5}+\delta_{R_{5}}^{-}-\delta_{R_{5}}^{+}=27,5 \\
& \mu_{5}+\left(\frac{\delta_{R_{1}}^{-}}{18}+\frac{\delta_{R_{1}}^{+}}{3}\right)=1 \\
& \mu_{6}+\left(\frac{\delta_{R_{2}}^{-}}{4}+\frac{\delta_{R_{2}}^{+}}{29}\right)=1 \\
& \mu_{7}+\left(\frac{\delta_{R_{3}}^{-}}{1}+\frac{\delta_{R_{3}}^{+}}{1,4}\right)=1 \\
& R_{6}+\delta_{R_{6}}^{-}-\delta_{R_{6}}^{+}=19 \\
& R_{7}+\delta_{R_{7}}^{-}-\delta_{R_{7}}^{+}=15,6 \\
& \mu_{1}+\frac{\left(\delta_{Y_{1}}^{-}+\delta_{Y_{1}}^{+}\right)}{0,5}=1 \\
& \mu_{2}+\frac{\left(\delta_{Y_{2}}^{-}+\delta_{Y_{2}}^{+}\right)}{2}=1 \\
& \mu_{3}+\frac{\left(\delta_{Y_{3}}^{-}+\delta_{Y_{3}}^{+}\right)}{100}=1 \\
& \mu_{8}+\left(\frac{\delta_{R_{2}}^{-}}{2}+\frac{\delta_{R_{2}}^{+}}{10,5}\right)=1 \\
& \mu_{9}+\left(\frac{\delta_{R_{5}}^{-}+\delta_{R_{5}}^{+}}{7,5}\right)=1 \\
& \mu_{10}+\left(\frac{\delta_{R_{6}}^{-}+\delta_{R_{6}}^{+}}{6}\right)=1 \\
& \mu_{11}+\left(\frac{\delta_{R_{7}}^{-}+\delta_{R_{7}}^{+}}{3,1}\right)=1 \\
& \mu, \delta_{y_{i}}^{-}, \delta_{y_{i}}^{+}, \delta_{X_{1}}^{-}, \delta_{X_{1}}^{+}, \delta_{R_{t}}^{-}, \delta_{R_{t}}^{+}, Y_{i}, X_{1} \text { and } R_{t} \geq 0
\end{aligned}
$$$$
\text { (For } i=1,2,3 \text { and } t=1,2, \ldots, 7) \text {. }
$$

Using the LINGO package, the obtained optimal solution is as follows:

$X_{1}=35, R_{1}=146,152, R_{2}=144, R_{3}=3,04, R_{4}=10$,

$R_{5}=20, R_{6}=29, R_{7}=17$
This solutions results to

$$
Y_{1}=16,54, Y_{2}=35, Y_{3}=5051,839
$$

The proposed model determines degree of membership functions for the ith goal:

$$
\begin{aligned}
& \left(\mu_{1}, \mu_{2}, \mu_{3}, \mu_{4}, \mu_{5}, \mu_{6}, \mu_{7}, \mu_{8}, \mu_{9}, \mu_{10}, \mu_{11}\right)= \\
& (1,1,1,1,0.341,1,0.971,1,0,1,0.509)
\end{aligned}
$$

We notice all the solutions lie within the target intervals, and that the model is simple and flexible that and its adaptation to every new situation. can accommodate the simultaneous the changes that can occur in models parameters (specification levels, the coefficients of the importance of deviation variables and membership functions), as Decision makers preferences can also be introduced to use all types of membership functions. Our model uses linear formulation directly contrary to the formulation of GP witch satisfaction function Which is very complex as it uses non-LP.

The Comparison between WAFGP - QCS model presented in this study, sengupta approach [11], FGP of Hannan (ADDITIVE and MINMAX Approach) and GP with satisfaction function indicated in Table 3.

Use of model WAFGP-QCS will depend largely on the goodness of the regression model because If the relationship between input characteristics, output characteristics and process parameters is week then the solution may deviate from the optimum, and depend also on type of membership functions.

Appendix : Fig. 3 presents the block diagram of the WAFGP-QCS model Development.

\section{Conclusions}

The QCS design is concerned with fixing the levels of inputs and process variables in order to meet a required specification of output, this problem can be tackled by using an imprecise GP model.

In this study we proposed an two formulations for designing a QCS based on Additive FGP model. First developed bay Hannan[4] Which uses a triangular linear membership functions and second developed by Yaghoobi and Tamiz [12]and Yaghoobi et al [13] named weighted additive fuzzy goal programming (WAFGP) Which uses all types of membership functions the proposed models are solved by using LINGO programme and getting optimal levels of input and process variables is to meet a required specification of output.

The major limitations of the proposed model concern the good quality of the regression model. If the relationship between input characteristics, output characteristics and process parameters is poor then the solution may deviate from the optimum. For future 
research we will use the fuzzy regression model developed by $\mathrm{H}$ Hassanpour et al [5] which will possible for us to uses it estimate of the relation between inputs variables, process variables and output variables.

Table 3: Comparisons between major QCS models

\begin{tabular}{|c|c|c|c|c|c|c|c|}
\hline & \multirow[b]{2}{*}{ variables } & \multirow[b]{2}{*}{$\begin{array}{c}\text { Target } \\
\text { intervalles }\end{array}$} & \multirow{2}{*}{$\begin{array}{l}\text { Sengupta } \\
\text { approach }\end{array}$} & \multicolumn{2}{|c|}{ Hannan Approach } & \multirow{2}{*}{$\begin{array}{c}\text { Approach } \\
\text { with } \\
\text { satisfaction } \\
\text { functions }\end{array}$} & \multirow[b]{2}{*}{ WAFGP-QCS } \\
\hline & & & & $\begin{array}{l}\text { MINMAX } \\
\text { Approach }\end{array}$ & $\begin{array}{l}\text { ADDITIVE } \\
\text { Approach }\end{array}$ & & \\
\hline $\begin{array}{l}\text { Input } \\
\text { characteristics }\end{array}$ & $\left(X_{1}\right)$ & {$[20,40]$} & 44 & 35,886 & 36,288 & 40 & 35 \\
\hline \multirow{7}{*}{ Process variables } & $\left(R_{1}\right)$ & {$[140,175]$} & 160 & 147,197 & 139,99 & 158 & 146,152 \\
\hline & $\left(R_{2}\right)$ & {$[140,173]$} & 176 & 146,789 & 156,502 & 145 & 144 \\
\hline & $\left(R_{3}\right)$ & {$[2,0,4,4]$} & 3 & 3,634 & 3,2 & 3,387 & 3,040 \\
\hline & $\left(R_{4}\right)$ & {$[8,0,20,5]$} & 11,5 & 10,570 & 11,605 & 9,321 & 10 \\
\hline & $\left(R_{5}\right)$ & {$[20,35]$} & 28 & 23,085 & 20 & 23 & 20 \\
\hline & $\left(R_{6}\right)$ & {$[13,25]$} & 23 & 22,249 & 18,99 & 23 & 19 \\
\hline & $\left(R_{7}\right)$ & {$[12,5,18,7]$} & 18 & 17,429 & 18,302 & 18,152 & 17 \\
\hline \multirow{3}{*}{$\begin{array}{l}\text { Output } \\
\text { characteristics }\end{array}$} & $\left(Y_{1}\right)$ & {$[16,18]$} & 16,42 & 16,455 & 17,04 & 16 & 16,54 \\
\hline & $\left(Y_{2}\right)$ & Close to 35 & 35,43 & 36,177 & 35 & 35 & 35 \\
\hline & $\left(Y_{3}\right)$ & Close to 5000 & 5910 & 5229,926 & 5056,86 & 5052,356 & 5051,83932 \\
\hline
\end{tabular}

\section{Acknowledgements}

The authors are grateful for the valuable comments and suggestions from the respected reviewers which have enhanced the strength and significance of our work

\section{References}

[1] Badri, M.A., A combined AHP-GP model for quality control systems. International Journal of Production Economics, Vol 72,2002, PP 27-40.

[2] Chanas, S and Kuchta, D. Fuzzy goal programming - One notation", many Meanings. Control and Cybernetics , Vol 31 ,2002, PP 871890.

[3] Sadok, C,M., Chabchoub,H., Aouni, B. Quality control system design through goal programming model and the satisfaction functions . European Journal of Operational Research, Vol 186, 2008, PP 1084-1098.

[4] Hannan, E.L., On fuzzy goal programming. Decision Sciences, Vol 12, 1981, PP 522-531.

[5] Hassanpour, H,. Male ki,H,R,. Yaghoobi,M,A., A Goal programming approach to fuzzy linear regression with non-fuzzy input and fuzzy output data ,Asia- Pacific Journal of Operational Research, Vol 26, 2009 , PP 587-604

[6] Kim, J.S., Whang, K.-S. A tolerance approach to the fuzzy goal programming problems with unbalanced triangular membership function .
European Journal of Operational Research , Vol 107, 1998, PP 614-624.

[7] Lee, C.S., Wen, C.G., Fuzzy goal programming approach for water quality management in a river basin . Fuzzy Sets and Systems, Vol 89, 1997, PP 181-192.

[8] Martel, J.M., Aouni, B., Incorporating the decision-maker's preferences in the goal programming model . Journal of Operational Research Society, Vol 41, PP 1121-1132.

[9] Narasimhan, R., Goal programming in a fuzzy environment . Decision sciences,Vol 11, 1980 ,PP 325-336.

[10] Schniederjans, M.J., Karuppan, C.M., Designing a quality control system in a service organization: A goal programming case study. European Journal of Operational Research, Vol 81, 1995, PP 249 258.

[11] Sengupta, S., Goal programming approach to a type of quality control problem. The Journal of the Operational Research Society, Vol 32 , 1981,PP 207-211.

[12] Yaghoobi,M,A.,and Tamiz. A methode for solving fuzzy goal programming problems with based on MINMAX approach . European Journal of Operational Research, Vol 177, 2007, PP1580 1590.

[13] Yaghoobi,M,A.,Jons,D,F., and Tamiz., 2008. Weighted additive models for solving fuzzy goal programming problems , Asia - Pacific Journal of Operational Research; Vol 25, 2007, PP 715-733. 
[14] Zadeh, L. A. Fuzzy Sets. Information and Control, Vol 8, 1965, PP 338-353.

\section{Appendix:}

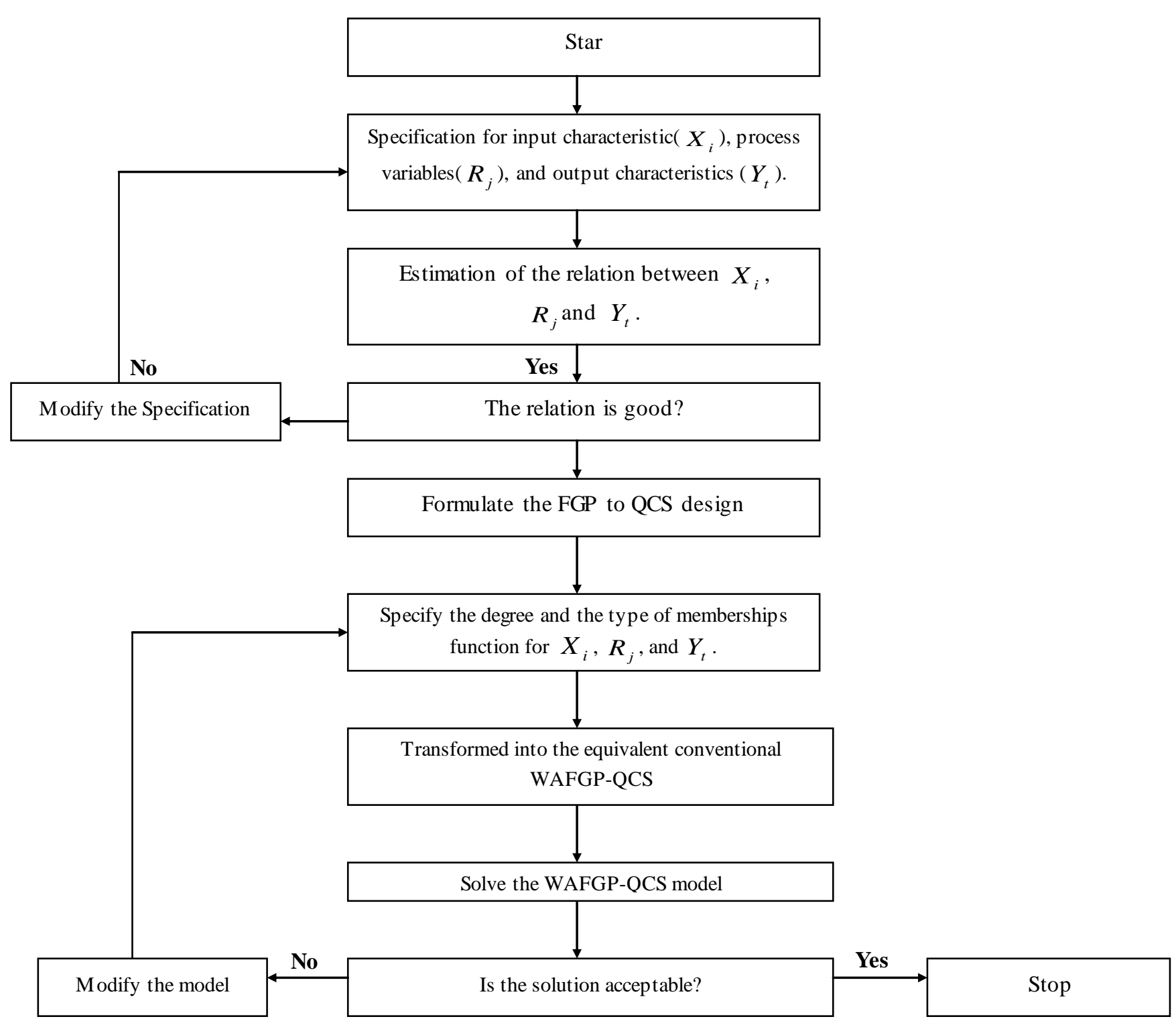

Fig. 3: The block diagram of WAFGP-QCS model development

\section{Authors' Profiles}

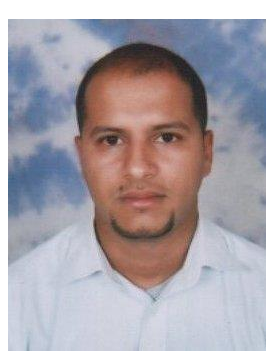

Mékidiche mohammed is currently Assistant Professor in the faculty of economics and commerce, University of Tlemcen, Maghnia Annex, Algeria, where he teaches Statistics and econometric, Operations Research, applied microeconomics and production planning, He received the MS degree and PH.D in production and operations Management from Economics and commerce Faculty,
University of Tlemcen in Algeria - .His research project is optimization in production planning, Multi Criteria Decision Making and Fuzzy Sets Theory, fuzzy goal programming, Quality control, Time series analysis and its application in forecasting, neural network and its application in management, He has published several articles in journals. 


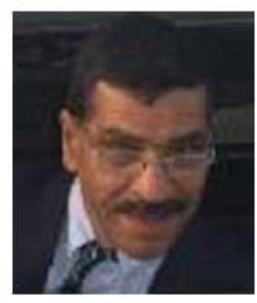

Mostefa Belmokaddem, Doctor of Economics, University professor - was graduate of the Faculty of Economics at the University of Oran in 1977 and worked as assistant lecturer and professor at the Faculty of Economics University of Tlemcen (Algeria). After receiving his Ph.D. (1982)in the Theoretical Statistics and Economics at the Academy of Economic Studies in Bucharest, he worked as a Lecturer at the Faculty of Economics, University of Tlemcen, Algeria, (19821989 ), Lecturer (1988-1990) and professor (1990 to present). He has participated in international scientific events and a summer school (Valencia, Spain). It presents his ideas on a wide band of key issues in microeconomics, the various techniques to aid decision making by providing useful information for each discipline and research projects. He is the author of handouts and has published several articles in journals. His research project is applied statistics and econometrics, fuzzy set, optimization, Goal programming, Multi criteria decision making.

How to cite this paper: Mohammed. Mekidiche., Mostefa Belmokaddem,"Application of Weighted Additive Fuzzy Goal Programming Approach to Quality Control System Design", International Journal of Intelligent Systems and Applications(IJISA), vol.4, no.11, pp.14-23, 2012. DOI: 10.5815/ijisa.2012.11.02 